\title{
The Role of Zamzam Water in Enhanced Apatite Growth - An In Vitro Study
}

\section{Suja Mathai*}

PG and Research Department of Chemistry, Mar Ivanios College (Autonomous), Thiruvananthapuram, Kerala, India

*Corresponding Author: Suja Mathai, PG and Research Department of Chemistry, Mar Ivanios College (Autonomous), Thiruvananthapuram, Kerala, India.
Received: July 30, 2021

Published: August 12, 2021

(C) All rights are reserved by Suja Mathai.

\section{Abstract}

Zamzam water has been scientifically proven to contain very high levels of Calcium and Magnesium, the water positively affects the human body, especially the bones as they absorb the vitamins and benefit from them for better growth. Zamzam water encourages the growth of healthy bones. The effect of Zamzam water for enhanced apatite growth and adhesion strength have been studied in the work by biomimetic method and were analysed using SEM-EDX, ICP-AES and potentiodynamic polarisation studies.

Keywords: Adhesion Strength; Apatite Growth; Biomimetic Method; Healthy Bones; Zamzam Water

\section{Introduction}

The biomimetic method [1,2] is one of the most promising techniques for the production of apatite crystals on bioactive surfaces. This method consists of soaking the implants under mild conditions of $\mathrm{pH}$ and temperature into simulated body fluid (SBF) solutions that have similar inorganic contents as human blood plasma $[3,4]$. The biomimetic approach has four main advantages: (1) it is a low temperature process (2) it forms bonelike apatite crystals having high bioactivity and good resorption characteristics (3) it is evenly deposited on, or even into pores or complex implant geometries and (4) it can incorporate bone-growth-stimulating factors $[5,6]$.

Producing bioactive titanium surface by immersing titanium (Ti) in a $\mathrm{NaOH}$ solution with a subsequent heat treatment have been invented by Kokubo., et al [7,8]. Apatite coatings have been successfully been formed by the immersion of the chemically treated Ti substrates $[9,10]$ in SBF solution. Several investigators carried out many studies to establish the influence of various ions present in SBF solution to apatite growth $[11,12]$.
Water is one of the main dietary components. Its quality plays an important role for the safety of food particularly for infants. The water from wells of Saudi Arabia is often high in mineral contents [13]. According to Arab historians, the Zamzam well has been in use for around 4000 years. The well is located within the Holy Mosque at about $20 \mathrm{~km}$ east of the Kaaba in Makkah [14]. Analysis of this water in the European laboratories give exemplary results that they contain high quantity of calcium and magnesium salts and also this water contains fluorides that they have an effective germicidal action. Moreover, they established that this water was fit for drinking [15]. This fact has also been proven by a group of Pakistani researchers. The present study aims to investigate whether Zamzam water can favors apatite growth and thereby establishing that regular intake of this water favors osseointegration.

In 1973 and 1989, great international specialized chemical companies carried out very accurate chemical analysis of Zamzam water. It was found that this water was absolutely free from all kinds of germs or viruses that causes water contamination due to high fluoride content. This water has never been chemically 
treated or chlorinates as in the case of water pumped into cities. Biological growth and vegetation usually take place in most wells. But in the case of the Zamzam water well, there was not any sign of biological growth. The antibacterial effect of the Hydroxyapatite (HAp) coated implants from SBF solution prepared in Zamzam water is also undertaken.

\section{Materials and Methods}

Commercially pure Ti (Sigma-Aldrich, England) substrates were cleaned with 150grit SiC paper, washed with ethanol, acetone and finally deionized water for 10 minutes. Immediately after words, the substrates were etched in $5 \mathrm{M} \mathrm{NaOH}$ solution for 24 hours at $60^{\circ} \mathrm{C}[1,16]$. Two SBF solutions were prepared (1) n-SBF (SBF solution prepared in normal water) and (2) ZZ-SBF. n-SBF were having the same ionic composition as that of human blood plasma and the composition in $\mathrm{mM}$ as $\mathrm{Na}^{+}: 142.0, \mathrm{~K}^{+}: 5.0, \mathrm{Mg}^{2+}: 1.5, \mathrm{Ca}^{2+}$ : 2.5, $\mathrm{Cl}^{-}: 103.0, \mathrm{HCO}_{3}{ }^{-}: 4.2, \mathrm{HPO}_{4}{ }^{2-}: 1.0$ and $\mathrm{SO}_{4}{ }^{2-}: 0.5$ [17]. The n$\mathrm{SBF}$ were prepared by adding salts of $\mathrm{NaCl}$ (Nice-99.9\%), $\mathrm{NaHCO}_{3}$ (Loba Chemie- 99.5-100\%), KCl (CDH-99.8\%), $\mathrm{K}_{2} \mathrm{HPO}_{4} .3 \mathrm{H}_{2} \mathrm{O}$ (Spectrum-98\%), $\mathrm{MgCl}_{2} \cdot 6 \mathrm{H}_{2} \mathrm{O}$ (Nice-98\%), $\mathrm{Na}_{2} \mathrm{SO}_{4}$ (Nice-99.5\%) and tris buffer $\left.\left(\mathrm{CH}_{2} \mathrm{OH}\right)_{3} \mathrm{CNH}_{2}\right)(\mathrm{SRL}-99.9 \%)$ to the deionised water.

ZZ-SBF were prepared by adding the required amounts of the salts to the Zamzam water. The alkaline and heat-treated Ti substrates were immersed in both n-SBF and ZZ-SBF at $36.5^{\circ} \mathrm{C}$ and $\mathrm{pH}$ : 7.4. The ratio of specimen surface area to soaking solution volume, S/V was $0.05 \mathrm{~cm}^{-1}$ [18] for 42 days. The surface potential change during biomimetic growth were monitored for 14 days by OCP measurements. The mechanical stability of the biomimetically grown apatite to the substrates were carried out by anodic polarization studies in $0.9 \% \mathrm{NaCl}$ solution. The phases of the coatings before and after biomimetic growth were determined by X-ray diffraction (XRD) (model: X-Pert Pro). In the XRD measurements $\mathrm{CuK} \alpha$ radiation at $40 \mathrm{KV}$ and $30 \mathrm{~mA}$ was used as the $\mathrm{X}$-ray source and the samples were scanned from $10-70^{\circ} 2 \theta$ at a scan rate of $1.2^{\circ}$ per min. The surface morphology and elemental composition of the coatings were evaluated using a scanning electron microscope (SEM) (JEOL-JSM-840A) coupled with energy dispersive spectroscope (EDS) and also by optical microscope (Olympus SZ61, Magnification X40). Elemental analysis of the SBF solution was carried out by Inductively coupled plasma spray atomic emission spectroscopy (ICP-AES) and spectrophotometry.

\section{Results and Discussions}

Figure 1 shows the surface potential change of the alkaline and heat-treated Ti during biomimetic growth in both n-SBF and ZZ$\mathrm{SBF}$ at $36.5^{\circ} \mathrm{C}$ and $\mathrm{pH}: 7.4$. In both the SBF's the initial potential was highly negative. Many researchers have given explanation for this. Ti metal is generally covered with a thin $\mathrm{TiO}_{2}$ layer, and hence is chemically durable. It has been found that the alkaline treated $\mathrm{Ti}$ forms sodium titanate $\left(\mathrm{Na}_{2} \mathrm{Ti}_{5} \mathrm{O}_{11}\right)$ surface layer. This sodium titanate could form many Ti-OH groups in SBF. When exposed to SBF, the $\mathrm{Na}^{+}$ions in the surface layer of $\mathrm{Na}_{2} \mathrm{Ti}_{5} \mathrm{O}_{11}$ are exchanged with $\mathrm{H}_{3} \mathrm{O}^{+}$ions present in the fluid facilitating the formation of $\mathrm{Ti}-\mathrm{OH}$ groups. Because of the negatively charged ions at the surface, the initial surface potential during biomimetic development in SBF solution was extremely negative [19]. The positively charged calcium $\left(\mathrm{Ca}^{2+}\right)$ ions from the SBF solution are preferentially attracted to this negatively charged surface, and the potential is shifted to the anodic direction. The negatively charged phosphate $\left(\mathrm{HPO}_{4}{ }^{2-}\right)$ ions are attracted to this positively charged surface, forming an amorphous $\mathrm{CaP}$ and the potential shifts negative. This CaP develops into crystalline apatite on its own. Because the SBF is significantly supersaturated in relation to apatite even under normal circumstances, the apatite develops spontaneously by up taking the calcium and phosphate ions in the fluid once created $[20,21]$.

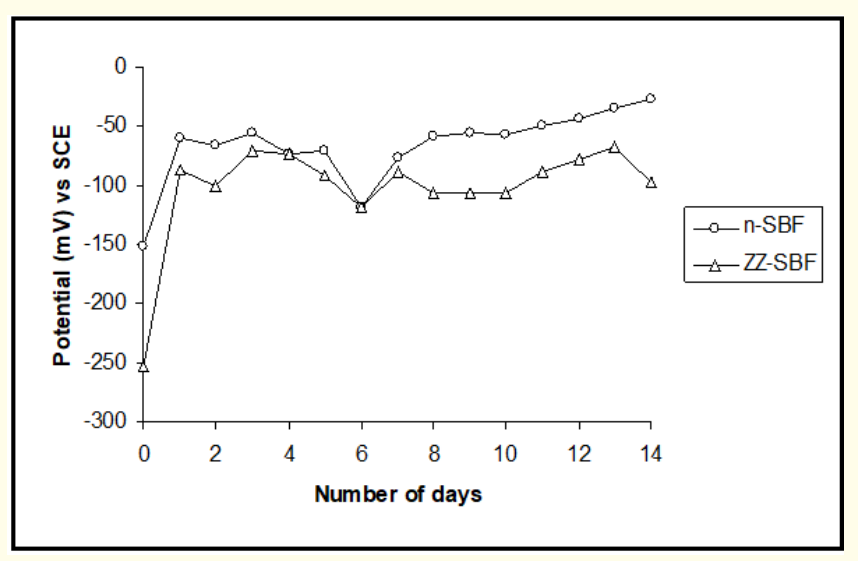

Figure 1: Surface potential change of the alkaline and heat-treated Ti during biomimetic growth in $(\circ)$ n-SBF and $(\Delta)$ ZZ-SBF at 36. $5^{\circ} \mathrm{C}$ and $\mathrm{pH}: 7.4$. 
Table 1 shows the mass \% of Ca and $\mathrm{P}$ on the surface of alkaline and heat-treated Ti after immersion in SBF solutions for 14 and 42 days at $36.5^{\circ} \mathrm{C}$. The mass $\%$ was found to be higher for the alkaline and heat-treated Ti immersed in ZZ-SBF for the two immersion times and this shows that higher amount of CaP crystals on the surface. This is an evidence for the influence of ZZ-water for enhanced apatite growth in living body environment also.

\begin{tabular}{|c|c|c|c|}
\hline \multirow{2}{*}{$\begin{array}{c}\text { Immersion } \\
\text { time }\end{array}$} & $\begin{array}{c}\text { Physiological } \\
\text { solution }\end{array}$ & \multicolumn{2}{|c|}{ Mass \% } \\
\cline { 3 - 4 } 14 days & $\mathrm{n}-\mathrm{SBF}$ & $\mathbf{P}$ \\
\cline { 2 - 4 } & $\mathrm{ZZ}-\mathrm{SBF}$ & 0.15 & 0.32 \\
\hline \multirow{2}{*}{42 days } & $\mathrm{n}-\mathrm{SBF}$ & 0.27 & 0.96 \\
\cline { 2 - 4 } & $\mathrm{ZZ}-\mathrm{SBF}$ & 0.69 & 1.33 \\
\hline
\end{tabular}

Table 1: Mass \% of Ca and $\mathrm{P}$ on the surface of alkaline and heat-treated Ti after immersion in SBF solutions.

Figure 2 shows the SEM micrograph and associated EDS pattern of (a) alkaline and heat-treated Ti; after biomimetic growth in nSBF and ZZ-SBF for 20 days and pH: 7.4. This shows the enhanced biomimetic growth character of the ZZ-SBF solution. The first CaP film deposited on the Ti surface acted as a seeding surface for further apatite growth. The high mass\% Ca and Mg in the ZZ-SBF increases the ionic activity product of the apatite in the narrow gap between the substrate and the bone surface.

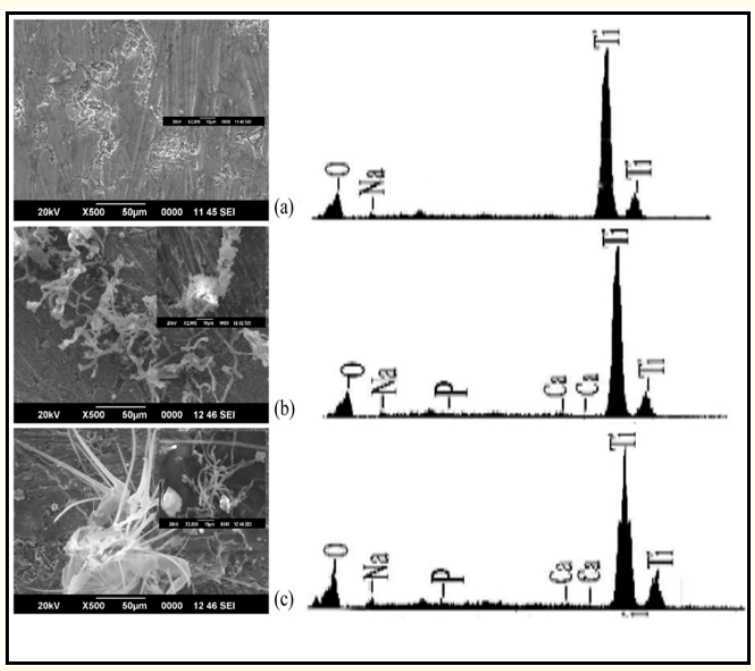

Figure 2: SEM micrograph and associated EDS pattern of (a) alkaline and heat-treated Ti; after biomimetic growth in (b) n-SBF (c) ZZ-SBF for 20 days and $\mathrm{pH}$ : 7.4.
Figure 3 shows the potentiodynamic anodic polarization curves of the HAp coatings on $\mathrm{Ti}$ in $0.9 \% \mathrm{NaCl}$ at $36.5^{\circ} \mathrm{C}$ and $\mathrm{pH}: 7.4$. From the polarization studies, the HAp coatings developed in ZZ-SBF could withstand aggressive conditions without delamination and shows the adhesive strength of the HAp coatings.

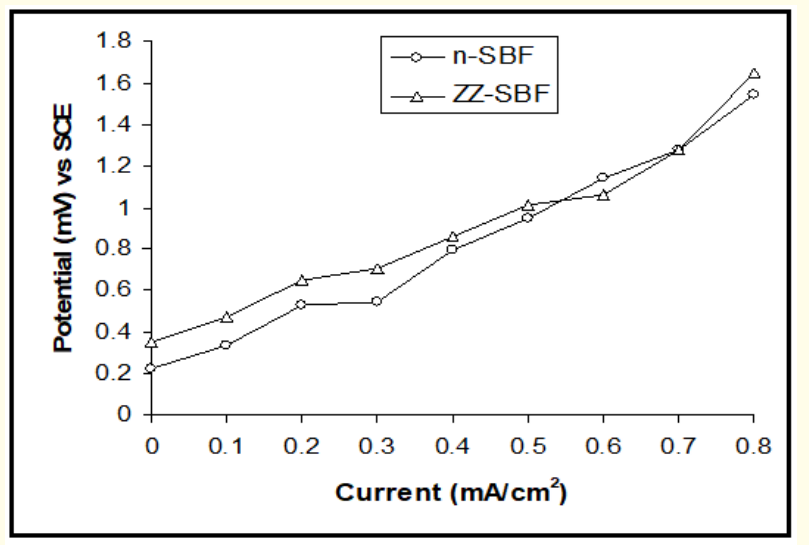

Figure 3: Potentiodynamic anodic polarization curves of the HAp coatings on $\mathrm{Ti}$ in $0.9 \% \mathrm{NaCl}$ solution at $36.5^{\circ} \mathrm{C}$ and $\mathrm{pH}: 7.4$. The coating developed in $(\circ) \mathrm{n}-\mathrm{SBF}$ and $(\Delta) \mathrm{ZZ}-\mathrm{SBF}$.

\section{Conclusion}

The alkaline and heat-treated $\mathrm{Ti}$ shows enhanced apatite growth in SBF prepared in Zamzam water. The HAp coatings developed in ZZ-SBF shows an enhanced adhesion strength even under aggressive conditions.

\section{Bibliography}

1. CM de Assis., et al. "Comparison of crystallinity between natural hydroxyapatite and synthetic cp-Ti/HA coatings". Materials Research 8 (2005): 207.

2. Barrere F., et al. "Biomimetic calcium phosphate coatings on Ti6Al4V. A crystal growth study of octa calcium phosphate and inhibition by Mg2+ and HCO3". Bone 25 (1999): 107-111.

3. Barrere F., et al. "Influence of ionic strength on the Ca-P coating formation from SBF x 5 solutions”. Biomaterials 23 (2002): 1921-1930.

4. Kokubo T., et al. "Solutions able to reproduce in vivo surfacestructure changes in bioactive glass-ceramics A-W-G". Journal of Biomedical Materials Research 24 (1990): 721-734. 
5. Habibovic P., et al. "Biomimetic hydroxyapatite coating on metal implants". Journal of the American Ceramic Society 85 (2002): 517-522.

6. Leeuwenburgh S., et al. "Osteoclastic resorption of biomimetic calcium phosphate coatings in vitro". Journal of Biomedical Materials Research 56 (2001): 208-215.

7. Lu X and Leng Y. "TEM study of calcium phosphate precipitation on bioactive titanium surfaces". Biomaterials 25 (2004): 1779-1786.

8. Kokubo T., et al. "Sponataneous formation of bonelike apatite layer on chemically treated titanium metals". Journal of the American Ceramic Society 79 (1996): 1127-1129.

9. Barrere F., et al. "Biomimetic coatings on titanium: a crystal growth study of octacalcium phosphate". Journal of Materials Science: Materials in Medicine 12 (2001): 529-534.

10. Li P., et al. "Bonelike hydroxyapatite induction by a gel-derived titania on a titanium substrate". Journal of the American Ceramic Society 77 (1994): 1307-1312.

11. Barrere F., et al. "Nucleation of biomimetic Ca-P coatings on Ti6Al4V from a SBF x 5 solution: influence of magnesium". Biomaterials 23 (2002): 2211-2220.

12. Barrere F., et al. "Fast formation of biomimetic CaP coatings on Ti6Al4V". Materials Research Society Symposium Proceedings 599 (2000): 135-140.

13. Challis DJ., et al. "Some effects of water quality on the performance of high yielding cows in an arid climate". Veterinary Record 120 (1987): 12-15.

14. Zamzam Studies and Research Centre. Cited from The Saudi Geological Survey. 5th June (2005).

15. Anlytical report of Zamzam water cited from the annual report of the ministry of agriculture and water resources (1971).

16. Vercik LCO., et al. "Dental implants: surface modification of CpTi using plasma-spraying and the deposition of hydroxyapatite". Materials Science Forum 416 (2003): 669-674.

17. Kokubo T and Takadama H. "How useful is SBF in predicting in vivo bone bioactivity?". Biomaterials 27 (2006): 2907-2915.

18. Jonasova L., et al. "Hydroxyapatite formation on alkali-treated titanium with different content of $\mathrm{Na}+$ in the surface layer". Biomaterials 23 (2002): 3095-3101.

19. Kim HM., et al. "Surface potential change in bioactive titanium metal during the process of apatite formation in simulated body fluid". Journal of Biomedical Materials Research 67A (2003): 1305-1309.

20. Takadama H., et al. "TEM-EDX study of mechanism of bonelike apatite formation on bioactive titanium metal in simulated body fluid". Journal of Biomedical Materials Research 57 (2001): 441-448.

21. Kim HM., et al. "Apatite-forming ability of alkali-treated Ti metal in body environment". Journal of the Ceramic Society of Japan 105 (1997): 111-116.

\section{Volume 4 Issue 9 September2021}

(C) All rights are reserved by Suja Mathai. 